\author{
BŁAŻEJCZYK KRZYSZTOF \\ Institute of Geography and Spatial Organization PAS \\ 51/55 Twarda Str., O0-818 Warszawa \\ E-mail:k.blaz@twarda.pan.pl
}

\title{
INFLUENCE OF CLIMATE CHANGE ON VULNERABLE ECOSYSTEMS AND SOCIETY. PREFACE
}

Climate change is a fact that worries the international community. The progressive increase in air temperature and the frequency and intensity of extreme weather events are felt by everyone. The Intergovernmental Panel on Climate Change (IPCC), under the auspices of the United Nations, has been collecting and analyzing information from scientific research for over 30 years. They concern both the phenomenon itself and its possible causes, as well as the impact of climate change on various ecosystems and various spheres of human life. In the scientific discourse, most researchers agree on the very existence of climate change and its consequences. Scientists do not fully agree to what extent climate change is caused by natural and to what extent - anthropogenic. Nevertheless, the view that human activity (mainly greenhouse gas emissions, deforestation, urbanization, industrialization and agriculture) is the main source of the changes that take place.

Demands to political groups to take decisive steps to slow down or at least limit the rate of temperature increase commonly appear in the social discourse. Political discussions on this subject are held at the annual Conferences of the Parties (COP), which are the highest body of the United Nations Framework Convention on Climate Change (UNFCCC), authorized to review its implementation, provisions and the adoption of legal instruments related to the convention. This year, the 26th COP session was held in Glasgow. Unfortunately, like many previous COP meetings, it did not bring significant progress in terms of climate protection and limiting its changes.

The editors of KOSMOS have been participating in the scientific discussion on climate change for several years. In 2008, a volume devoted to global warming and its effects (Kosmos 57, 3-4, Climate changes and their impacts), and in 2013, one of the articles (Kosmos, 62, 1, 1-11) of the journal dedicated to the 25th anniversary of the work of the IPCC were published. In the current issue of KOSMOS, the reader will find four articles devoted to the impact of climate change on the functioning of selected, vulnerable ecosystems and on the socially important issue of health protection. The presented texts cover various time horizons. The longest of them covers the last 5,000 years. Two texts present contemporary climate changes taking place in sensitive ecosystems (polar and marshy areas). The last of these texts looks to the future and addresses the possible health consequences of climate change. The intention was to write a text on climate change in high-mountain areas. Unfortunately, the author's illness made it impossible to prepare it.

The text by K. Muslih and K. Błażejczyk shows different temporal views on climate change in the desert and semi-desert areas of the Middle East. On the basis of various indirect sources, the authors present the development of the climate in the period 3000-0 BC (before Christ). During this period, the climate fluctuated many times (from cool to hot and from dry to humid). These changes had a significant impact on the social, political and economic development of the area, causing the colapses and rise of several civilizations in the Mesopotamian area. The instability of the climate in this area is also visible today. It is illustrated by fluctuations in precipitation and temperature, and these fluctuations are influenced, similarly to the period 3000-0 BC, by changes in atmospheric circulation, both in the North Atlantic (NAO index) and in the 
North-Western Indian Ocean. These fluctuations also have an impact on the functioning of Middle Eastern societies today.

The text of S. and M. Słowiński concerns the problems of the functioning of peatland ecosystems in the zone of temperate and cool climate. Based on their own research and the research of other researchers, the Authors present the interactions between the observed climate changes and the functioning of peatlands. In their considerations, they refer not only to contemporary processes, but also try to reconstruct these changes on the basis of paleoclimatic research, using drilling conducted in various regions of the Northern Hemisphere. The Authors emphasize that only the integration of paleoclimatic studies and the observation of modern processes will allow the determination of turning points and trajectories of changes for peatlands.

Discussion of the important issue of climate change in polar ecosystems was undertaken by a group of Polish polar explorers led by A. Araźny. In their deliberations, they use not only the results of historical and experimental research, but also their own experiences from their stays in the Arctic and Antarctica. According to the Authors, the observed climate changes in the polar regions affect the terrestrial and marine ecosystems. The expected consequences of warming in the Arctic and Antarctic "include reduction of thickness and surface area of continental ice sheets, reduction of the surface of mountain glaciers, loss of sea ice surface and perennial permafrost and snow cover. This deglaciation is changing the coastline and coastal area of the land areas". Climate changes, and in particular an increase in temperature, cause changes in fauna and flora, which are manifested by shrub vegetation entering the polar areas. On the other hand, the positive effect of warming the polar regions is the improvement of the perceived weather conditions for humans.

A look at the climate of the future is complementary to the research on historical and contemporary research on climate change. It was done by A. Błażejczyk and J. Baranowski by analyzing how the chang- ing climate will affect the health of the society in Poland in the coming decades of the 21st century. They used the results of the project: Assessment of the impact of climate change on the health of society in various regions of Poland and the forecast until 2100 , which they carried out in 2012-2015. These studies are based on a retrospectiveprognostic scheme. Based on historical data, the Authors developed statistical models of the impact of various climate features on the number of cases and deaths in the socalled climate related diseases. In the second stage, they used the forecasts of climate change according to SRES scenarios (A1, A1B and B2) assuming different pace of climate change. They found statistically significant increases in such diseases as: skin cancer, Lyme disease or deaths from circulatory causes and heat-related deaths. On the other hand influenza infections and respiratory deaths are expected to decline.

The importance of climate and its changes in the functioning of vulnerable ecosystems and societies is again highlighted by the recently published 6th IPCC Report. The conclusions of the present collection of studies are also clearly highlighted in this Report. Regarding mountain ecosystems, subsequent IPCC reports, including the latest one, state that they are exposed to a whole range of challenges resulting from climate change, affecting changes in climatic-and-vegetation belts, including threats to endemic mountain plant species. These challenges are related to the progressive increase in temperature, loss of snow cover and mountain glaciers, or the increase in extreme rainfall and the resulting flash floods. These changes are global and are observed on all continents.

Obviously, the presented set of texts does not exhaust the entire issue of the influence of climate on the functioning of vulnerable ecosystems and the functioning of societies. We believe, however, that they clearly speak of the need to intensify the actions of the international community to stop, or at least slow down, climate change. Otherwise, we risk destroying the biodiversity of ecosystems, as well as socially and economically costly efforts to ensure future generations can live and develop.

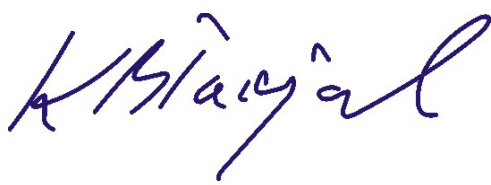

